\title{
Gas chromatographic-mass spectrometric determination of azithromycin in biological fluids
}

\author{
Subbiah Thangadurai
}

\begin{abstract}
Background: Azithromycin monohydrate is an antibiotic, which belongs to the category of macrolide antibiotics. It is used for an effective antibiotic for the treatment of sexually transmitted diseases, upper and lower respiratory tract infections and skin structure infections.

Methods: A gas chromatographic-mass spectrometric (GC-MS) method is described for the determination of azithromycin monohydrate residue in biological fluids. This method allows detection of residual azithromycin (AZM) in biological fluids by using single-ion monitoring (SIM). The confirmation by a full-scan electron impact (El) mass spectrum is possible if residual level in a sample is $>5 \mu \mathrm{g} / \mathrm{mL}$. AZM is extracted with chloroform from a sample and cleaned up by $n$-hexane washing followed by partition between chloroform and phosphate buffer solution. The cleaned up extract is acetylated in acetic anhydride-pyridine mixture (1:2) at room temperature.
\end{abstract}

Results: The reaction mixture is injected into the GC-MS apparatus, and the detection has been conducted using SIM at $\mathrm{m} / \mathrm{z}$ 200. The detection limit is $2 \mu \mathrm{g} / \mathrm{mL}$.

Conclusions: This proposed method could be successfully applied to the drug analysis in the forensic laboratories as well as in the toxicological laboratories.

Keywords: Azithromycin; Biological fluids; Extraction; Derivatization; GC-MS; SIM

\section{Background}

Antibiotics are now used extensively in food-producing animals to maintain optimal health and to promote growth. The use of these drugs can leave drug residues in edible tissues. These drug residues may have direct toxic effects moreover; safety considerations may include allergic reactions of consumers and induction of resistant bacteria. Therefore, conditions of use must be established for animal drugs to assure human food safety as well as efficacy and safety to the animal species (Livingston 1985).

Azithromycin (AZM), with a different chemical entity (so-called azalide) from the macrolides, is also derived from erythromycin, but the lactone ring is expanded from 14-membered to 15 -membered, by the incorporation of nitrogen. As in erythromycin, cladinose and desosamine sugar residues are attached at positions 3 and 5 . AZM exhibits a more extensive spectrum of activity,

\footnotetext{
Correspondence: drstdurai@gmail.com
}

Post Graduate Studies and Research Department of Chemistry, Raja

Doraisingam Government Arts College, Government of Tamil Nadu, 630561 Sivagangai, India

\section{Springer}

(c) 2015 Thangadurai; licensee Springer. This is an Open Access article distributed under the terms of the Creative Commons Attribution License (http://creativecommons.org/licenses/by/4.0), which permits unrestricted use, distribution, and reproduction in any medium, provided the original work is properly credited. greater acid stability and more favourable pharmacokinetic parameters than erythromycin.

AZM is an effective antibiotic for the treatment of sexually transmitted diseases, upper and lower respiratory tract infections and skin structure infections (Kirst and Sides 1989). It is also used primarily to treat various bacterial infections caused by respiratory pathogens, such as aerobic Gram-positive and Gram-negative bacteria. It prevents bacterial cells from manufacturing specific proteins necessary for their survival. AZM is rapidly absorbed and is widely distributed to tissues and becomes concentrated in cells. Peak plasma concentrations are achieved (Debremaeker et al. 2003) within 2 to $3 \mathrm{~h}$.

AZM is obtained from erythromycin, impurities present will undergo the same modifications and the AZM analogues of these impurities can be found in AZM bulk samples. In addition, degradation products of AZM as well as intermediate compounds (Khedr and Sheha 2003) of the semi-synthesis may be present; for instance, AZM is rapidly decomposed in acidic solution via intra-molecular dehydration to form erythromycin-6, 6-hemiketal and then 
anhydroerythromycin (Fiese and Steffen 1990). It is also very difficult to determine (Miguel and Barbas 2003) small amounts of degradation products in a vast excess of parent drug and even more so when the compounds do not present a chromophore as this makes their detection more difficult.

Chromatographic methods using both thin-layer chromatography (TLC) and liquid chromatography (LC) have been described for the determination of macrolide antibiotics. The application of these methods to residue analysis has been limited. To overcome this lack of sensitivity and selectivity, TLC and LC methods have been developed; a review was found on these methods (Moats 1985). However, TLC methods are capable of qualitative detection of only one drug in one type of food. LC has also been used for determination of macrolide antibiotics, but application to residue analysis has been limited. A stability-indicating TLC method of the analysis of AZM in bulk and a capsule form is developed (Khedr and Sheha 2003).

Both coulometric and amperometric methods for the detection of AZM in human and animal tissues and serum were used (Shepard et al. 1991). The coulometric method has since been used by a number of investigators to characterize the pharmacokinetics of AZM in humans (Ripa et al. 1996; Conte et al. 1996). HPLC with ultraviolet detection has been used for the analysis of AZM in bulk samples, for the separation of related compounds produced during synthesis and for acid degradation studies. Methods for the HPLC analysis of AZM in biological samples have also been described using various methods of detection in order to overcome the limitations of poor UV absorbance.

A sensitive HPLC assay using a $\mathrm{C}_{18}$ stationary phase with detection by atmospheric pressure chemical ionizationmass spectrometry (APCI-MS) has been developed (Fouda and Schneider 1995), specifically for the analysis of AZM in children, which requires only a minute sample volume of $50 \mu \mathrm{L}$. A selective reversed-phase liquid chromatography/ mass spectrometry (LC/MS) method has been developed for the identification of AZM impurities and related substances in commercial AZM samples (Debremaeker et al. 2003). In comparison with UV detection, this hyphenated technique provides as its main advantage efficient identification of novel substances without time-consuming isolation and purification procedures.

The purpose of this work is to briefly describe mass spectrometry techniques that are commonly used to solve toxicological problems. Often a gas chromatographic-mass spectrometric (GC-MS) quantitative assay is developed and used as a primary standard for evaluation of less expensive assay methods. Most GC-MS quantitative analyses involve the operation of the mass spectrometer in the selected ion monitoring mode (Falkner et al. 1975).
Methods used to determine AZM residue levels include, but are not limited to, microbiological and chromatographic techniques such as TLC and GC. However, microbiological methods lack specificity and TLC methods lack sensitivity. Microbiological assays are most commonly used for the measurement of AZM in food, but they are time consuming, they cannot identify certain macrolides and their precision appears to be variable. Therefore, a precise chromatographic analysis method for the macrolides has been required.

This paper describes a GC-MS method for the determination of AZM residue in biological fluids. This method allows detection of residual AZM in biological fluids by using single-ion monitoring. This method could be applied in the forensic laboratories and toxicological laboratories as well as in pharmaceutical formulations.

\section{Methods}

\section{Chemicals and materials}

All reagents and solvents used were of analytical grade.

Azithromycin was received from Hindustan Antibiotics Ltd., Bangalore, India, as a free gift sample. Acetic anhydride and anhydrous pyridine were obtained from Merck (Darmstadt, Germany) and was pro analysis grade. Deionized, doubly distilled water was used throughout.

TLC silica gel $F_{254}$ plate was obtained from Merck (Darmstadt, Germany).

Standard reagents viz. methanol $\left(\mathrm{CH}_{3} \mathrm{OH}\right), n$-hexane $\left(n-\mathrm{C}_{6} \mathrm{H}_{6}\right)$, chloroform $\left(\mathrm{CHCl}_{3}\right)$, sodium hydroxide $(\mathrm{NaOH})$, sodium chloride $(\mathrm{NaCl})$, sodium sulfate $\left(\mathrm{Na}_{2} \mathrm{SO}_{4}\right)$ and disodium hydrogen phosphate $\left(\mathrm{Na}_{2} \mathrm{HPO}_{4} \cdot 12 \mathrm{H}_{2} \mathrm{O}\right)$ all used were AR grade.

\section{$\mathrm{Na}_{2} \mathrm{HPO}_{4}$ solution}

One gram of disodium hydrogen phosphate $\left(\mathrm{Na}_{2} \mathrm{H}-\right.$ $\mathrm{PO}_{4} \cdot 12 \mathrm{H}_{2} \mathrm{O}$ ) was taken from a beaker and then dissolved in $100 \mathrm{~mL}$ of doubly distilled water.

\section{$\mathrm{NaOH}$ solution}

A $5 \mathrm{~N}$ sodium hydroxide $(\mathrm{NaOH})$ solution was prepared using $20 \mathrm{~g}$ of $\mathrm{NaOH}$ and dissolved in $100 \mathrm{~mL}$ of doubly distilled water.

\section{$\mathrm{NaCl}$ solution}

Ten grams of sodium chloride $(\mathrm{NaCl})$ was taken from a beaker and dissolved in $100 \mathrm{~mL}$ of doubly distilled water.

\section{Standard solutions Stock solution}

Accurately weighed $100 \mathrm{mg}$ of pure azithromycin monohydrate was dissolved in the methanol; the solution was made up in the 10-mL standard flask to make the concentration $10 \mathrm{mg} / \mathrm{mL}$. 


\section{Working solution}

Standard solutions were diluted to $50,25,10,5$ and $2 \mu \mathrm{g} / \mathrm{mL}$ concentration with methanol from the above stock solution. These solutions have been stored in a refrigerator with light protection.

\section{Extraction and cleanup}

Gastric cleavage samples $(10 \mathrm{~mL})$ were taken from a $100-\mathrm{mL}$ centrifuge tube. Then, $20 \mathrm{~mL}$ of $\mathrm{CH}_{3} \mathrm{OH}$ was added into that, and then it has been homogenized for $10 \mathrm{~min}$. The contents were rinsed twice well with $3 \mathrm{~mL}$ of $\mathrm{CH}_{3} \mathrm{OH}$, and the rinses were added into the centrifuge tube.

The centrifuge tube has been shaken very well for $10 \mathrm{~min}$. The supernatant solution was filtered through fluted paper into a $100-\mathrm{mL}$ separatory funnel. Twenty milliliters of $\mathrm{CH}_{3} \mathrm{OH}$ was added into the residue; the centrifuge tube was shaken vigorously for $10 \mathrm{~min}$.

The contents were centrifuged for $10 \mathrm{~min}$ at $2000 \mathrm{rpm}$; after that, the supernatant solution was filtered through fluted paper. The filtrate was combined with the first extract, which is in a 100-mL separatory funnel.

Further, $20 \mathrm{~mL}$ of $n$-hexane was added into the combined $\mathrm{CH}_{3} \mathrm{OH}$ extract, which is in a separatory funnel, it has been shaken vigorously for $5 \mathrm{~min}$, and it was set aside to separate.

The lower $\mathrm{CH}_{3} \mathrm{OH}$ phase was drained into a second 100 -mL separatory funnel, and the upper $n$-hexane phase was discarded. Two to three milliliters of $1 \mathrm{~N} \mathrm{NaOH}$ and $30 \mathrm{~mL}$ of $\mathrm{CHCl}_{3}$ were added into the $\mathrm{CH}_{3} \mathrm{OH}$ phase, and these were mixed by swirling.

In addition to this, $30 \mathrm{~mL}$ of $1 \%$ of $\mathrm{Na}_{2} \mathrm{HPO}_{4}$ solution was also added, and it has been shaken vigorously for 2-3 min. It was set aside to separate for 15-20 min. The lower $\mathrm{CHCl}_{3}$ phase was drained into a third $100-\mathrm{mL}$ separatory funnel.

Suppose if two phases do not readily separate after centrifugation for $5 \mathrm{~min}$ at $2000 \mathrm{rpm}$, we have to add an additional $30 \mathrm{~mL}$ of $\mathrm{CHCl}_{3}$ into the aqueous phase and it should be extracted again. The $\mathrm{CHCl}_{3}$ extract was combined into the third $100-\mathrm{mL}$ separatory funnel, and it was washed with $30 \mathrm{~mL}$ of $\mathrm{NaCl}$ solution.

The $\mathrm{CHCl}_{3}$ phase has been transferred into a $100-\mathrm{mL}$ round bottom flask, and the solvent has been evaporated at $40-45{ }^{\circ} \mathrm{C}$.

\section{Instrumentation}

\section{GC column}

The capillary column was $5 \%$ phenyl methyl silicone, with $30-\mathrm{m}$ width, $0.25-\mathrm{mm}$ i.d. and 0.25 film thickness.

\section{Gas chromatograph mass spectrometer}

The gas chromatograph mass spectrometer was a PerkinElmer instrument with Autosystem XL GC, turbo mass MS, autosampler, $2-\mu \mathrm{L}$ injection, $200^{\circ}$ injection port, $200^{\circ}$ interface, $70-\mathrm{eV}$ electron impact (EI) mode and 40-630-amu mass range.

\section{Operating conditions}

The operating conditions were as follows: $200^{\circ}$ injection port, $250^{\circ} \mathrm{C}$ oven isothermal temperature, $1 \mathrm{~mL} / \mathrm{min}$ carrier gas helium flow and $70-\mathrm{eV}$ ionization voltage.

\section{Derivatization procedure}

For successful GC-MS analysis, the sample must be both volatile and thermally stable. Many organic compounds do not fulfil these criteria by virtue of their possessing polar functional groups. Protecting these functional groups by derivatization is the normal method for conferring good GC-MS behaviour. Derivatization is used to increase a compound's volatility or its thermal stability to improve its GC behaviour by substituting lipophilic groups for 'active' hydrogens or to advantageously alter the compound's mass spectrum (Lin et al. 2008).

The derivatization reactions generally used for GC determination are silylation, acetylation and etherification. In this work, we have chosen to utilize the acetyl derivative, because it is easily prepared and stable, and the increase in molecular weight by derivatization is not so

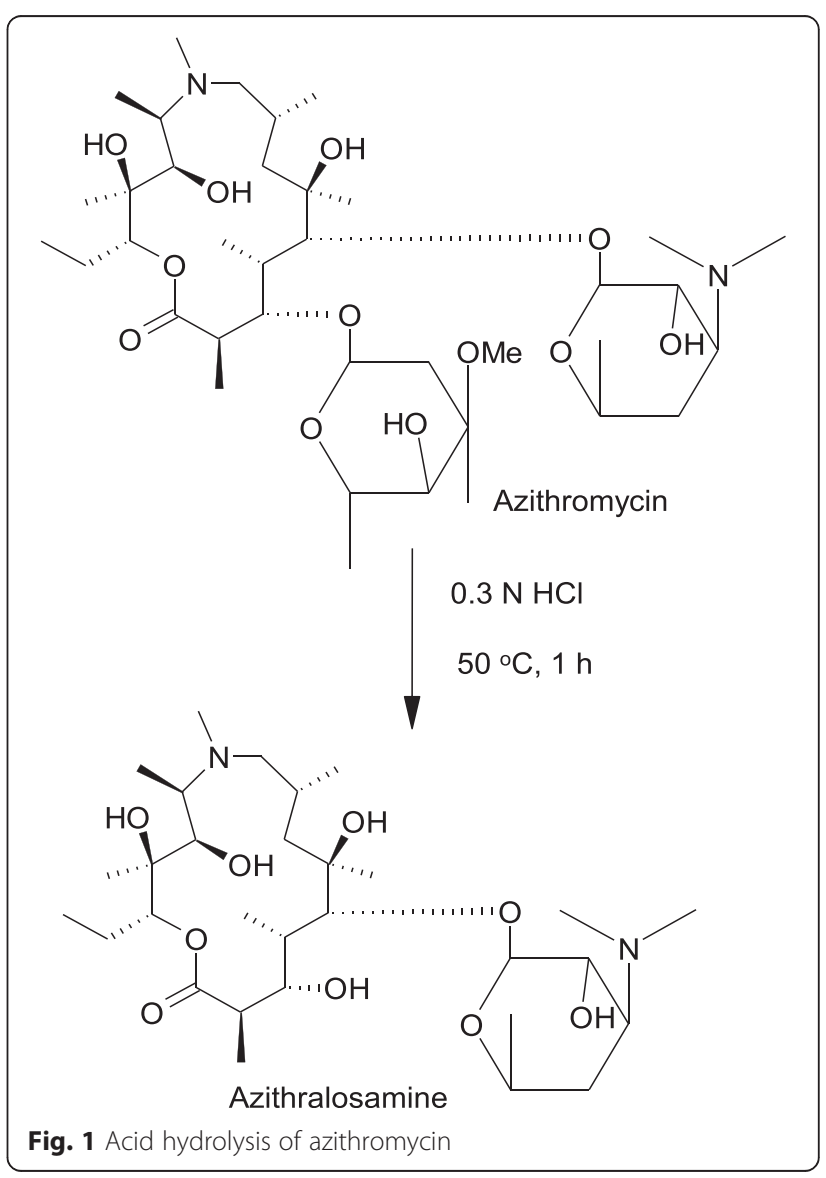




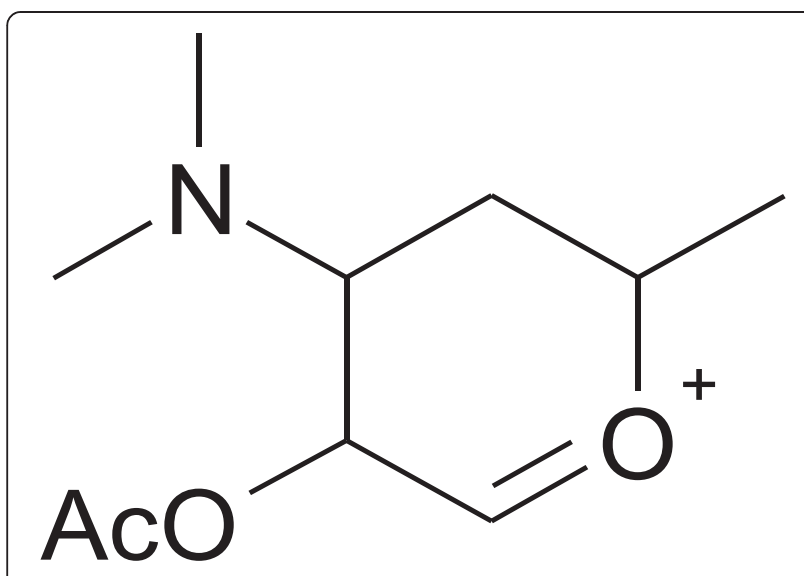

Fig. 2 Structure for $\mathrm{m} / \mathrm{z} 200$ fragmentation of desosamine acetate in El mass spectrum of the azithralosamine acetate

large. Azithralosamine was acetylated using acetic anhydride and pyridine at room temperature. The reaction mixtures were monitored by TLC to ensure the complete conversion of starting materials. At high temperatures, it was possible to elute azithralosamine acetate as a relatively sharp peak in a reasonable retention time. In an autosampler vial, $1 \mathrm{~mL}$ of working solution containing a concentration of $5 \mu \mathrm{g} / \mathrm{mL}$ was pipetted out. It was evaporated to dry, and the dry residue was dissolved in $500 \mu \mathrm{L}$ of anhydrous pyridine; in addition to the pyridine solution, $250 \mu \mathrm{L}$ of acetic anhydride was added and the vial was closed tightly. The residue was dissolved by swirling and allowed to stand at room temperature overnight. This sample solution has been reserved in a refrigerator. This is ready for injection into the GC-MS apparatus.

\section{Evaluation of repeatability, reproducibility and linearity} The repeatability of the derivatization procedure and the chromatographic analysis was determined by five replicate injections of the standards prepared as described above. The reproducibility of the method was determined by five replicate injections performed within 3 days.

The reproducibility of the derivatization procedure and the chromatographic analysis was checked by repetition of the first average separate determinations. The calibration curves were linear in the tested range up to $500 \mu \mathrm{g} / \mathrm{mL}$.

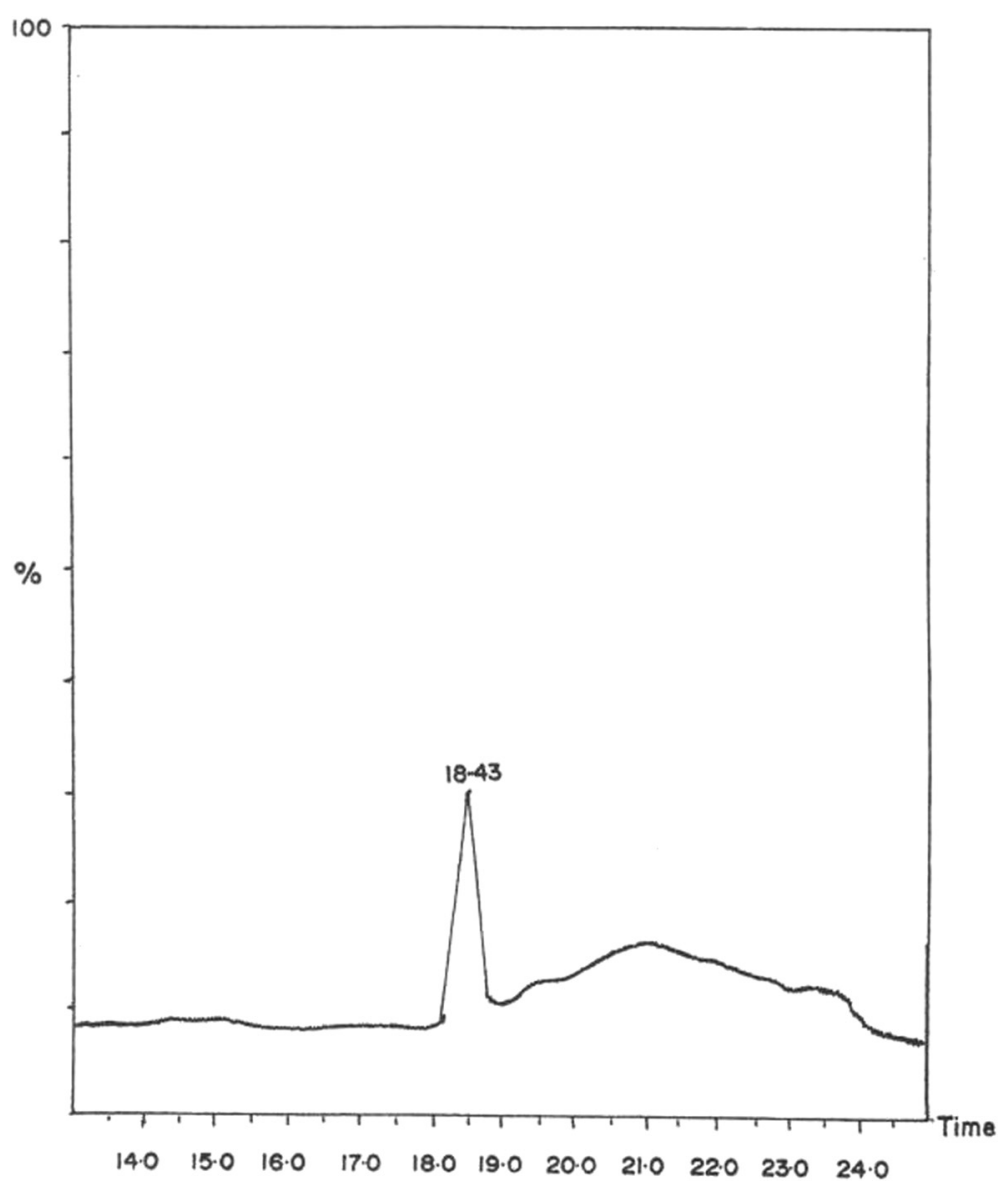

Fig. 3 Single-ion chromatogram at $\mathrm{m} / \mathrm{z} 200$ for azithralosamine acetate 


\section{Results and discussion}

The molecular weight is relatively large $(M . W=749)$ for AZM. This antibiotic has polar functional groups such as hydroxyls, carbonyls and sugars. Elution from a GC column after derivatization was considered to be difficult and impractical. At first, we intended to obtain the aglycone of AZM by hydrolyses of all glycoside linkages. However, the glycoside linkage of the amino sugar, desosamine, resists acid hydrolysis much more than that of the neutral sugar, cladinose. A condition normally required for the removal of desosamine from the macrolides induces destruction of the aglycone. On the other hand, azithralosamine can be easily obtained by mild acid hydrolysis (Fig. 1) encouraging us to do GC-MS determination after derivatization.

The conditions of acid hydrolysis for AZM was investigated using TLC (silica gel $\mathrm{F}_{254}$, dichloromethane:methanol =9:1). But no separation for AZM drugs was obtained. For this purpose (Wallhäuser KH 1967), a slow moving solvent mixture containing water and $n$-butanol had to be used, needing about $1 \mathrm{~h}$ to give an elution zone of $6 \mathrm{~cm}$. With longer distances, separation of AZM was not improved. In contrast to dichloromethane:methanol mixtures, the $R_{f}$ values of AZM spots did not change

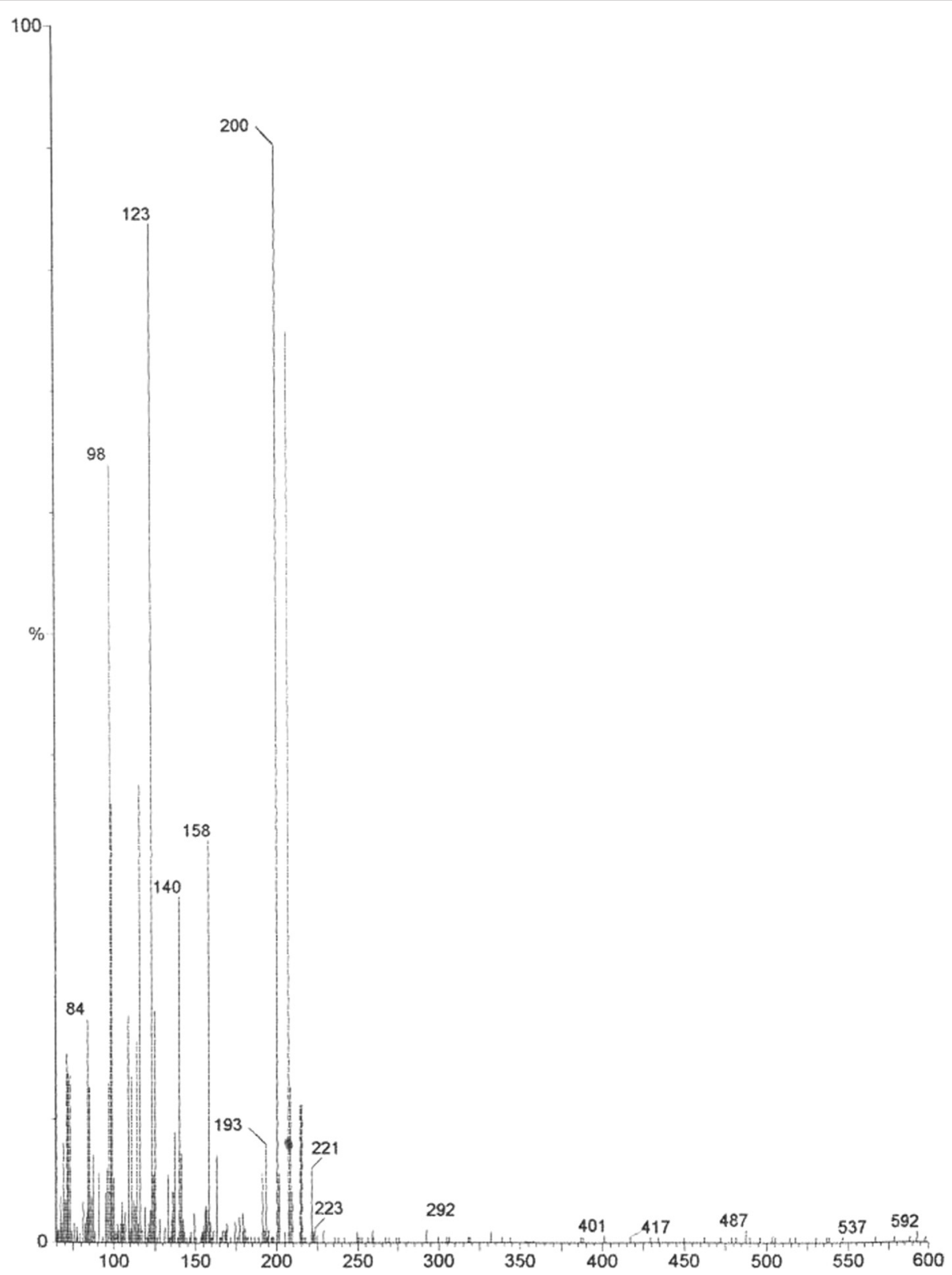

Fig. 4 Electron impact mass spectrum of azithralosamine acetate (70 eV) at a retention time of $18.43 \mathrm{~min}$ 
when coextractives from tissues were present. The $R_{f}$ values with $n$-butanol:water $(9: 1 v / v)$ for AZM is 0.42 . Optimum conditions obtained were $0.1 \mathrm{~N} \mathrm{HCl}$ at room temperature and overnight reaction time. To shorten the reaction time, slightly more vigorous conditions were tried. We found that heating at $50{ }^{\circ} \mathrm{C}$ in $0.3 \mathrm{~N} \mathrm{HCl}$ for $1 \mathrm{~h}$ was sufficient to obtain comparable yield of azithralosamine.

The reproducibility of the derivatization procedure and the chromatographic analysis was checked by repetition of the five average separate determinations. The calibration curves were linear in the tested range up to $500 \mu \mathrm{g} / \mathrm{mL}$. The acetylation at an elevated temperature is faster than that at room temperature. The amount of acetylated product decreased to about half after 2 weeks of storage in the refrigerator. Our experiences indicated that the GC-MS determination must be performed within 2-3 days after acetylation.

Azithralosamine acetate was injected into the GC-MS apparatus, and total ion chromatogram and a full-scan mass spectrum were obtained. Figure 4 shows the mass spectrum, in which the base peak of $m / z 200$ is very prominent and $m / z 84,98,123,140,158,193,207,221,223$, 292, 401, 417, 487, 537 and 592 are observed but relatively weak. The $m / z 200$ ion is considered to be the desosamine acetate ion (Fig. 2). Simultaneous monitoring of three ions is usually regarded as a minimum for identification by selected ion monitoring of GC-MS spectra (Sphon 1978). In this work, we attempted to detect azithralosamine acetate using selected ion monitoring at $m / z 200,98,123,140$, 158, 193, 207 and 221. However, the sensitivity of detection is much lower $(<1 / 10)$ than that using single-ion monitoring (SIM) at $m / z 200$ only. There are no interfering peaks on this chromatogram at the retention time of azithralosamine acetate.

For extraction of AZM from sample tissues, we used methanol because of the high solubility of macrolides and the ease of permeability into sample tissues. To remove coextractives and to clean up the antibiotic, we washed methanol extract with $n$-hexane and partitioned between chloroform and phosphate buffer. Figure 3 shows the SIM chromatogram of AZM hydrolysis and acetylation at $\mathrm{m} / \mathrm{z}$ 200. The peak observed is very close to that of azithralosamine acetate. Figure 4 shows the full-scan mass spectrum of the peak indicated at a retention time of 18.43. However, many background ions appeared on the full-scan mass spectrum of this peak and confirmation was not possible.

\section{Conclusions}

Although an internal standard is not used in this method, the separation of the GC column and the sensitivity of SIM detection considered together offer the reliable screening of residual AZM in biological fluids, and a confirmation of the presence of AZM in samples of high residue level is possible. The focus of our research however has been on methods allowing the confirmation of AZM in biological fluids. This method could be applied in the determination of macrolide group of antibiotics in forensic samples as well as in toxicological and in the environmental samples.

Competing interests
The author declare that he has no competing interests.

\section{Authors' contributions}

I have performed the experimental and analytical work and prepared the draft of the manuscript. The guidelines and supervision of this work was provided by the Central Forensic Science Laboratory, Directorate of Forensic Science (DFS), Ministry of Home Affairs, Govt. of India, CFI's Complex, Ramanthapur, Hyderabad 500 013, India. I have read and approved the final manuscript.

\section{Authors' information}

My research areas of interest are geochemistry, pharmaceutical and medicinal chemistry and forensic chemistry.

\section{Acknowledgements}

I am very grateful to the Director, Central Forensic Science Laboratory (CFSL), Directorate of Forensic Science (DFS), Ministry of Home Affairs, Govt. of India, CFI's Complex, Ramanthapur, Hyderabad 500 013, India, for providing the necessary facilities to carry out this work and for giving constant encouragement throughout the work.

Received: 21 April 2015 Accepted: 11 May 2015

Published online: 23 May 2015

\section{References}

Conte JE, Golden J Jr, Duncan S, McKenna E, Lin E, Zurlinden E (1996) Single-dose intrapulmonary pharmacokinetics of azithromycin, clarithromycin, ciprofloxacin, and cefuroxime in volunteer subjects. Antimicrob Agents Chemother 40(7):1617-1622

Debremaeker D, Visky D, Chepkwony HK, Van Schepdael A, Roets E (2003) Analysis of unknown compounds in azithromycin bulk samples with liquid chromatography coupled to ion trap mass spectrometry. Rapid Commun Mass Spectrom 17:342-350

Fouda HG, Schneider RP (1995) Quantitative determination of the antibiotic azithromycin in human serum by HPLC-atmospheric pressure chemical ionization mass spectrometry: correlation with a standard HPLC electrochemical method. Ther Drug Monit 17:179-183

Falkner FC, Sweetman BJ, Watson JT (1975) Biomedical application of selected ion monitoring. Appl Spectrosc Rev 10:51-57

Fiese EF, Steffen SH (1990) Comparison of the acid stability of azithromycin and erythromycin A. J Antimicrob Chemother 25(Suppl A):39-47

Khedr A, Sheha M (2003) Quantitative thin layer chromatographic method of analysis of azithromycin in pure and capsule forms. J Chromatogr Sci 41:10-16

Kirst HA, Sides GD (1989) New directions for macrolide antibiotics: pharmacokinetics and clinical efficacy. Antimicrob Agents Chemother 33:1419-1422

Livingston RC (1985) Antibiotic residues in animal-derived food. J Assoc Off Anal Chem 68(5):966-967

Lin DL, Wang SM, Wu CH, Chen G, Liu RH (2008) Chemical derivatization for the analysis of drugs by GC-MS-A conceptual review. J Food Drug Anal 16(1):1-10

Miguel L, Barbas C (2003) LC determination of impurities in azithromycin tablets. J Pharm Biomed Anal 33:211-217

Moats WA (1985) Chromatographic methods for determination of macrolide antibiotic residues in tissues and milk of food-producing animals. J Assoc Off Anal Chem 68(5):980-984

Ripa S, Ferrante SL, Prenna M (1996) A linear model for the pharmacokinetics of azithromycin in healthy volunteers. Chemotherapy 42(6):402-409

Shepard RM, Duthu GS, Ferraina RA, Mullins MA (1991) High-performance liquid chromatographic assay with electrochemical detection for azithromycin in serum and tissues. J Chromatogr 565(1-2):321-337

Sphon JA (1978) Use of mass spectrometry for confirmation of animal drug residues. J Assoc Off Anal Chem 61:1247-1252

Wallhäuser KH (1967) Antibiotika. In: Stahl E (Hrsg). Dünnschicht-Chromatographie. Springer Verlag. Berlin. S. 545 